MATEC Web of Conferences 53, 01016 (2016)

DOI: $10.1051 /$ matecconf/20165301016

(C) Owned by the authors, published by EDP Sciences, 2016

\title{
Flexural Behavior of Textile-Reinforced Concrete
}

\author{
Anna Volkova ${ }^{1}$, a, Alexey Paykov ${ }^{1}$, Sergey Semenov ${ }^{1}$, Oleg Stolyarov ${ }^{1}$ and Boris Melnikov ${ }^{1}$ \\ Peter the Great St.Petersburg Polytechnic University, Polytechnicheskaya 29, 195251 St.Petersburg, Russia
}

\begin{abstract}
This paper deals with the flexural behaviour of textile-reinforced concrete (TRC). Two samples of TRC made of high strength reinforcing fabrics made of glass and carbon rovings were produced. Three-point bending test was carried out to examine the flexural performance of the developed samples. The maximum flexural strength and reinforcement efficiency were calculated. Experimental results showed that that all types of applied fabric reinforcement contributed to increases strength as compared to nonreinforced concrete. Furthermore, the deformation behavior of reinforced concrete was analyzed. The advantage is in higher residual load-bearing capacity, which allows maintaining the integrity of the structure.
\end{abstract}

\section{Introduction}

Different types of high-strength textile materials are finding new applications for the reinforcement of structural parts [1-4]. For their manufacture, high strength and high modulus fibers and filaments, such as basalt, glass, carbon and others are generally used [2]. In combination with the cement matrix, they present a new class of structural building materials - Textile-reinforced concrete. Appeared relatively recently, textile-reinforced concrete is becoming one of the most promising materials used in construction. Compared to traditional building materials textile-reinforced concrete has a number of advantages including high corrosion resistance, minimal concrete covering, light weight, etc. However, its use is often limited by the high cost of initial reinforcement materials, whereby the use of such concrete structures in massive constructions is not economically feasible. Therefore, such reinforcement usually finds effective use in various structural elements, which combine lightweight, small size and strength, for example, sandwich panels, and also can be used in the reconstruction of various concrete structures.

The use of high-strength textile materials for the reinforcement of concrete structures has many advantages, one of which is the production of concrete elements sufficiently thin compared to conventional concrete. In addition to this entire textile reinforcement has greater flexibility and drape.

\footnotetext{
${ }^{a}$ Corresponding author: volkova-anna-andreevna@mail.ru
} 
The reinforcing fibers for reinforced concrete include alkali-resistant glass fibers (AR-glass), also basalt and carbon fibers. These fibrous fillers may be used in the form of chopped (staple) fibers or in the form of fabric with open cells structure. Unlike discrete fibrous fillers, the yarn and rovings made of continuous filaments in the form of textile fabric can fully implement the properties of high strength and high-modulus filaments. The mechanism of the reinforcing fibers in the cement matrix is greatly different from that which occurs in the polymer matrix because of the lower ultimate elongation of the cement matrix, which is significantly less than the elongation of the fibers. Therefore, in the cement composites, the matrix breaks up before the strength properties of the fibrous reinforcement will be fully realized. In polymer composites, the matrix is generally more flexible than the fiber. A significant advantage is also the fact that the fiber will be able to sustain the load after the formation of cracks and fracture of the matrix.

Fabric reinforced concrete is a planar or spacer structure consisting of a particular geometrical mesh shape to facilitate penetration of the cement into the structure. The form of mesh cells of reinforcing fabric may have different shapes: rectangle, diamond, triangle, and others. The size and shape of cells may be different. The most common rectangular cells have sizes of 8, 10, 16 and 20 $\mathrm{mm}$. Bonding to the concrete matrix, and as a consequence, the mechanical properties of reinforcement depend on the mesh size of the fabric. The larger cell size leads to greater probability that there will not be any cavities inside of the concrete reducing its strength characteristics. Over the past two decades, many works have been devoted to this topic. In work [3], the systematic approach to the study of concrete reinforced fiber composites is described. In general, it comprises:

1) The test material;

2) Analysis of the properties;

3) The calculation of the best combination of strength and fracture toughness; Statistical analyses and calculations of strength.

In [4-6], the method of measurement and application of structures of reinforced concrete composites and method of production of reinforcement fibers and fabrics are presented. The dependence of the strength characteristics of the composite on the structural parameters of the reinforcement rovings and fabrics were considered in [7-9]. In [10, 11], the use of polymers in a composite concrete is described. The possibility of using carbon fiber materials and composites based on them in concrete structures was considered in [12]. Various methods for the reinforcement of composites, such as the casting of concrete into the mold of the fabric and using a mixture of steel and non-metallic fibers are discussed in [13, 14]. In studies [15-18], various models, such as the computer model of the composite structure of concrete, models describing the behavior of the structure under the influence of prolonged stress and corrosion were analysed. Existing methods to strengthen reinforced concrete superstructure, including the strengthening of composite materials based on carbon fibers in the polymer matrix are investigated in [19]. Increased durability of concrete structures can also be accomplished using prestressed textile fabrics described in [20,21].

A review of the literature has shown that the main advantages of using high-strength reinforcing textiles consist in the increasing strength characteristics, particularly in cases of large loads on thin elements); improving durability and reducing the costs of structures and other materials used in the construction to obtain the same strength characteristics as in the application of composites; an increase in the carrying capacity of the structural elements; increased fracture toughness, and smaller cracks.

\section{Experimental}

\subsection{Materials}

The main aim of this research is to study the possibility of using high-strength reinforcing fabrics made of glass and carbon rovings for textile reinforced concrete. In this work, two types of warp- 
knitted reinforcing fabrics made of glass and carbon rovings were used. The characteristics of the specimens are presented in Tab. 1.

Table 1. Characteristics of reinforcing materials.

\begin{tabular}{|c|c|c|c|c|c|c|}
\hline \multirow[t]{2}{*}{ № } & \multicolumn{4}{|l|}{ Reinforcing roving } & \multicolumn{2}{|l|}{ Fabric } \\
\hline & Machine direction & $\begin{array}{c}\text { Cross- } \\
\text { machine } \\
\text { (transverse) } \\
\text { direction }\end{array}$ & $\begin{array}{c}\text { Tensile } \\
\text { strength, } \mathrm{MPa}\end{array}$ & $\begin{array}{c}\text { Young's } \\
\text { Modulus, } \\
\mathrm{MPa}\end{array}$ & Cell size & $\begin{array}{c}\text { Surface } \\
\text { density, } \\
\mathrm{g} / \mathrm{m} 2\end{array}$ \\
\hline 1 & $\begin{array}{l}\text { AR-glass, 4K, } 2400 \\
\text { tex }\end{array}$ & \multirow[t]{2}{*}{ AR-glass } & $1024,0 \pm 60,3$ & $66,5 \pm 2,0$ & $8 \times 8 \mathrm{~mm}$ & 620 \\
\hline 2 & $\begin{array}{l}\text { Carbon (PAN-based } \\
\text { fiber), } 24 \mathrm{~K}, 1600 \text { tex }\end{array}$ & & $2093,0 \pm 73,4$ & $173,0 \pm 4,3$ & $8 \times 8 \mathrm{~mm}$ & 510 \\
\hline
\end{tabular}

The structure of the reinforcing fabric presents an open-grid structure with rectangular cells created by the roving laid in two directions connected with thin knitting polyester yarn with a linear density of 15.6 tex. The fabric included a glass (specimen 1) or carbon (specimen 2) rovings in longitudinal direction, and only glass rovings in the transverse direction. The mesh size was $8 \times 8 \mathrm{~mm}$, with $50 \mathrm{~mm}$ accounted for 6 rovings. The structures used in the reinforcing fabrics of glass and carbon rovings are shown in Fig. 1a and 1b, respectively.

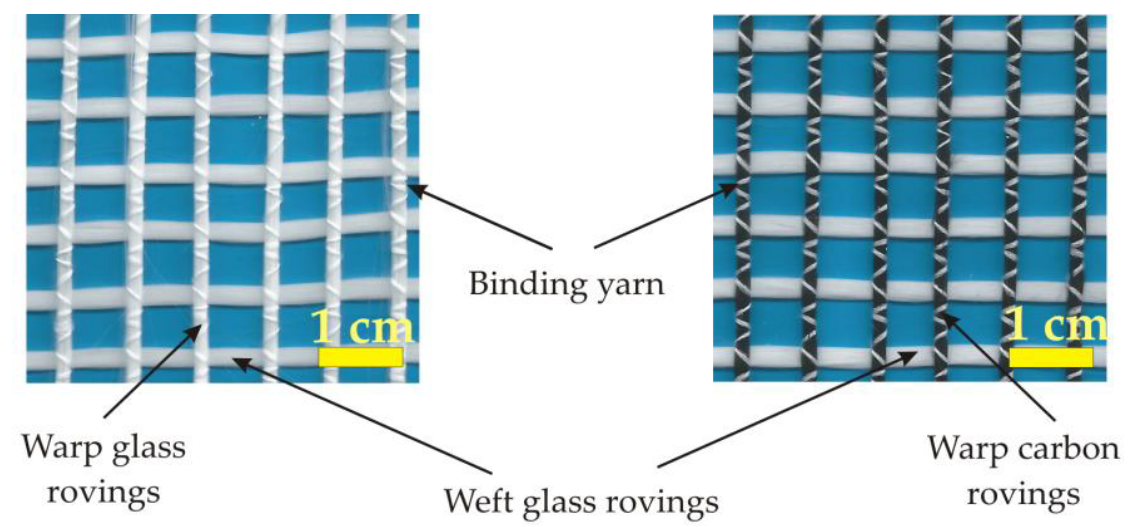

a)

b)

Figure 1. Structure of the warp-knitted reinforced fabrics

\subsection{Fabrication of textile-reinforced concrete}

Fine-grained concrete with a maximal sand fraction of $0.63 \mathrm{~mm}$ was used to manufacture the concrete composite samples. The specimens were casted in the mold $(56 \times 200 \times 20 \mathrm{~mm})$. Two samples of the reinforced fabrics were placed in the tension and compression areas at a distance of $2 \mathrm{~mm}$ from each edge. The test samples were stored for 28 days at $23^{\circ} \mathrm{C}$ and $95 \% \mathrm{RH}$ before testing. 


\subsection{Three-point bending test of concrete}

Samples of textile-reinforced concrete were tested in a three-point bending test (Fig. 2). The flexural tests were carried out in a Instron 5965 testing machine at a clear span of $150 \mathrm{~mm}$. The specimens were constantly loaded at a rate of $1 \mathrm{~mm} / \mathrm{min}$.

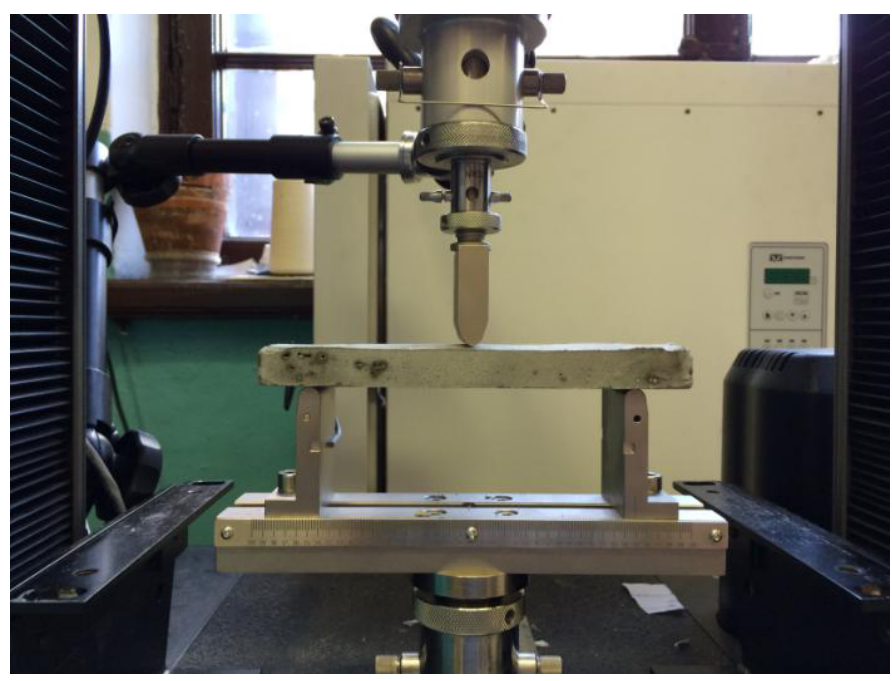

Figure 2. Three-point bending test of concrete

According to the test results the bending strength was determined as the ratio of the maximum bending moment of the specimen to the axial section modulus in bending by the equation

$$
\sigma=\frac{M_{b}}{W_{z}},
$$

where $\mathrm{M}_{\mathrm{b}}$ - maximum bending moment, $\mathrm{kN} * \mathrm{~m} ; \mathrm{W}_{\mathrm{z}}-$ moment of inertia, $\mathrm{m}^{3}$.

\section{Results and discussions}

\subsection{Flexural behaviour}

Fig. 3 shows the stress-deflection curves of three-point bending test of reinforced cement composites. From the diagrams it is clear that the behavior of reinforced and non-reinforced specimens is different. Moreover, the flexural behaviour greatly depends on the type of the reinforcing roving. The samples of textile-reinforced concrete show similar flexural behavior. The initial part of the deformation is characterized by a linearity of properties with the subsequent transition to a section with a slight nonlinearity. After this there is a first transverse crack. In the case of AR-glass-reinforced specimens, magnitude of this load is the maximum on the stress-deflection curve. A specimen reinforced with carbon rovings shows flexural load corresponding to the first crack of approximately equal to the strength of nonreinforced concrete. Then, an increase in bending stress due to the load-bearing capacity of carbon fibers is observed. This process occurs in steps to produce a few more of the maximum peaks. 


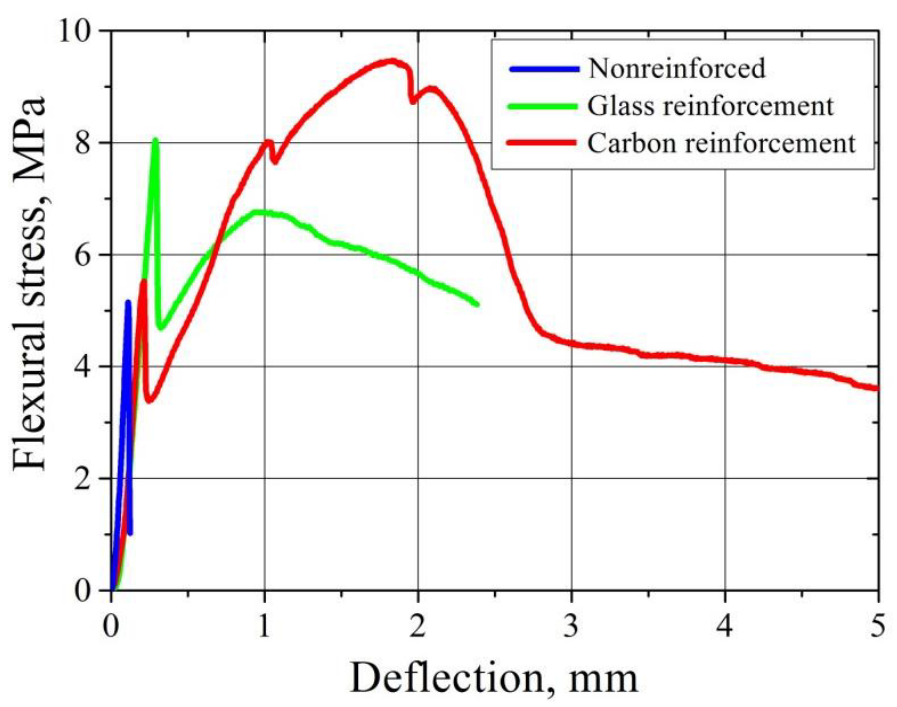

Figure 3. The stress-deflection curve of textile reinforced concrete with different roving type

Results of flexural strength are shown in Fig. 4. During the analysis of the results, it can be noted that the bending strength of reinforced concrete is $5.2 \mathrm{MPa}$. Application of reinforcing fabric gives a certain increase in flexural strength. The strength of the specimens reinforced with AR-glass is 8.1 $\mathrm{MPa}$, and for specimens reinforced with carbon rovings is $9.5 \mathrm{MPa}$. However, as can be seen from the curves presented in Fig. 3, the first peak in the stress-deflection curve of the AR-glass specimen is the same as the flexural strength of the non-reinforced concrete specimen. While in the specimen reinforced with carbon roving, the first peak value was about 0.5 of the flexural strength. Further, with increasing deflection, an increase in load due to resist rovings is observed. This ability to maintain the shape and performance without breaking at very large strains can be used in critical areas, such as those associated with the seismic resistance of buildings and structures.

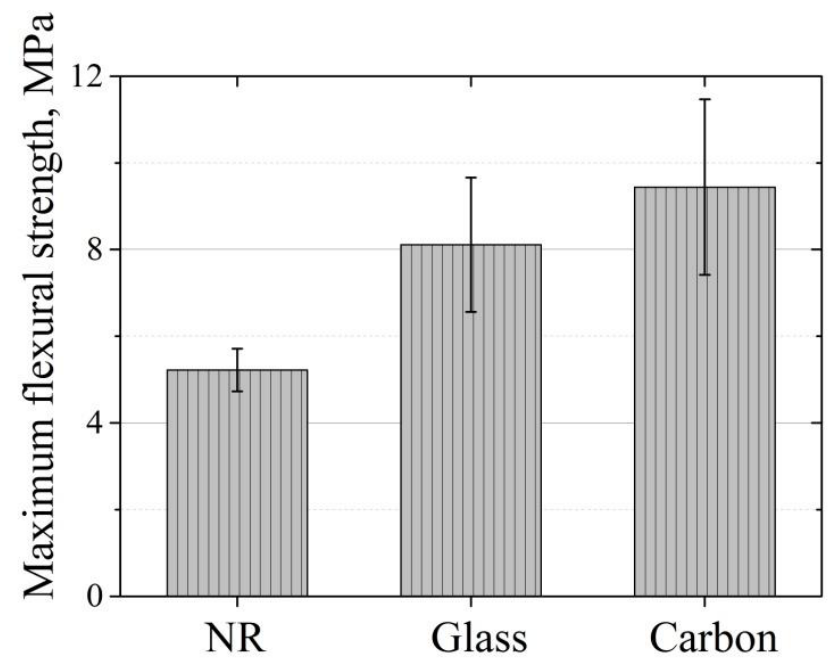

Figure 4. Maximum flexural strength 


\section{MATEC Web of Conferences}

\subsection{Reinforcement efficiency}

The reinforcement efficiency of the developed samples may be evaluated by a factor indicating the ratio of reinforced concrete's flexural strength to the flexural strength of the nonreinforced reference sample. This ratio is calculated as

$$
k_{R E}=\frac{\sigma_{r d}}{\sigma_{n r}},
$$

where $\sigma_{\text {rd }}$ is the flexural strength of a reinforced concrete (MPa) and $\sigma_{\text {nr }}$ is the flexural strength of a reinforced concrete $(\mathrm{MPa})$.

The results obtained from the Eq. 2 are shown in Fig. 5. As can be seen from the data, the reinforcement efficiency depends on the type of roving. For the specimen manufactured of AR-glass rovings, the flexural strength increased by 1.55 times, and for the specimen manufactured of carbon rovings, an increase in flexural strength is 1.81 times. It is evident that there is a certain effect of reinforcement with applying the high-strength textile fabrics. However, by the results of tests it is difficult to evaluate the validity of the results, because the scatter of values for flexural strength for reinforced specimens is very significant. This is well illustrated by the standard deviation at the histograms for specimens of reinforced concrete.

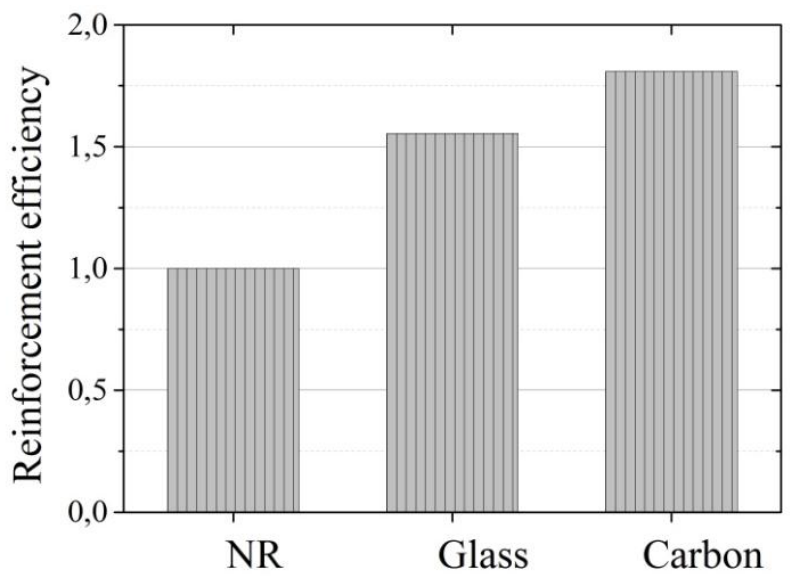

Figure 5. Maximum flexural strength (a) and the reinforcement efficiency

\subsection{Statistical analysis}

In order to assess the accuracy of the results a statistical analysis for the significant difference based on the Student t-test was carried out. Results are presented in Tab. 2. Analyzing the statistics of the average values of the maximum flexural strength, a significant difference is observed in some pairs (bold font) at the 0.05 level. The results show that between series of nonreinforced concrete and reinforced concrete on the basis of glass or carbon rovings the significant difference is observed. However, a comparison between the results of a series of specimens with glass and carbon rovings differences are not significant. 
Table 2. Statistical analysis.

\begin{tabular}{|c|c|c|c|c|}
\hline \multirow{2}{*}{ Parameter } & The reinforcing component & Unreinforced & AR-glass & Carbon \\
\hline \multirow{3}{*}{ Flexural strength } & Unreinforced & & $\mathbf{0 , 0 1 1 9}$ & $\mathbf{0 , 0 0 5 1}$ \\
\cline { 2 - 5 } & AR-glass & & & 0,3168 \\
\cline { 2 - 5 } & Carbon & & & \\
\hline
\end{tabular}

\section{Conclusions}

It is proved that the specimens with textile reinforcement have higher strength properties than the original specimens. Reinforcement efficiency was calculated using the proposed coefficient $\mathrm{k}_{\mathrm{re}}$ and is given depending on the type of reinforcing fabric. The flexural behavior of reinforced concrete was analysed. It is shown that the specimens are reinforced with high-strength textile fabrics have greater residual load-bearing capacity so as to maintain the structural integrity is not destroyed after the maximum applied loads. A significant difference between the results of a series of reference specimens and reinforced specimens was found. However, the comparison of flexural strength between the reinforced specimens made of glass and carbon rovings showed no significant differences. However, in general it may be noted the obvious advantages of using textile reinforcement consisting mainly of high residual load-bearing capacity of the material.

\section{References}

1. O. Stolyarov, A. Gorshkov, Magazine of Civil Engineering, 4, 21-25 (2009)

2. O. Stolyarov, T. Quadflieg, T. Gries, Textile Research Journal, 85 (18), 1934-1945 (2015)

3. I. Löfgren, Fibre-reinforced Concrete for Industrial Construction. Department of Civil and Environmental Engineering, Structural Engineering, (Chalmers University Of Technology, Göteborg, (2005)

4. $\quad$ V.V Okrepilov, A.Yu. Smirnov, Measurement Techniques, 56 (1), 54-60 (2013)

5. S. Voss, J. Hegger, ICTRC, 1-10 (2006)

6. S. Voss, 6th International PhD Symposium in Civil Engineering, 1-8 (2006)

7. A. Peled, Z. Cohen, Y. Pasder, A. Roye, Cement \& Concrete Composites, 30, 174-183 (2008)

8. M. Horstmann, A. Shams, J. Hegger, CTRS6, 329-340 (2011)

9. C. Kulas, J. Hegger, M. Raupach, U. Antons, CTRS6, 329-340 (2011)

10. D. Kurlapov, A. Kuvaev, A. Rodionov, R. Valeev, Magazine of Civil Engineering, 3, (2009)

11. A. Keil, M. Raupach, 12th International Congress on Polymers in Concrete, 873-881 (2007)

12. N. Paranicheva, T. Nazmeeva, Magazine of Civil Engineering, 2, (2010)

13. M. Al A. Ghaib, J. Go'rski, Cement and Concrete Research, 31, 1459-1465 (2001)

14. A. Sivakumar, M. Santhanam, Cement \& Concrete Composites, 29, 603-608 (2007)

15. S. Holler, C. Butenweg, S.-Y. Noh, Computers and Structures, 82, 1971-1979 (2004)

16. J. Orlowsky, Modeling the Long-term Behavior of Textile Reinforced Concrete. (IBAC, (2010)

17. J. Orlowsky, M. Raupach, Corrosion Modeling of AR-glass Reinforcement in Textile Reinforced Concrete (IBAC, (2010)

18. J. Orlowsky, M. Raupach, Materials and Structures, 39, 635-643 (2006)

19. I. Ovchinnikov, S.Valiev, I. Ovchinnikov, V. Zinov’ev, A. Umirov, Internet-magazine «Science studies», 4, (2012)

20. H. W. Reinhardt, M. Kruger, C. U. Crobe, Journal of Advanced Concrete Technolog, 3, 231-239 (2003)

21. A. Peled, Cement and Concrete Research, 37, 805-813 (2007) 